\title{
Machine Learning Approach Effectively Predicts Binding Between SARS-CoV-2 Spike and ACE2 Across Mammalian Species - Worldwide, 2021
}

\author{
Yue $\mathrm{Ma}^{1, \alpha<} ; \mathrm{Yu} \mathrm{Hu}^{1,2,2,}$; Binbin $\mathrm{Xia}^{1} ; \mathrm{Pei} \mathrm{Du}^{1}$; Lili Wu${ }^{1} ;$ Mifang Liang ${ }^{3}$; Qian Chen ${ }^{1,4}$; \\ Huan Yan'; George F. Gao'; Qihui Wang ${ }^{1, *}$; Jun Wang ${ }^{1, *}$
}

\begin{abstract}
Introduction: Severe acute respiratory syndrome coronavirus 2 (SARS-CoV-2) is a recently emergent coronavirus of natural origin and caused the coronavirus disease (COVID-19) pandemic. The study of its natural origin and host range is of particular importance for source tracing, monitoring of this virus, and prevention of recurrent infections. One major approach is to test the binding ability of the viral receptor gene ACE2 from various hosts to SARS-CoV2 spike protein, but it is time-consuming and laborintensive to cover a large collection of species.

Methods: In this paper, we applied state-of-the-art machine learning approaches and created a pipeline reaching $>87 \%$ accuracy in predicting binding between different ACE2 and SARS-CoV-2 spike.

Results: We further validated our prediction pipeline using 2 independent test sets involving $>50$ bat species and achieved $>78 \%$ accuracy. A large-scale screening of 204 mammal species revealed 144 species (or $61 \%$ ) were susceptible to SARS-CoV-2 infections, highlighting the importance of intensive monitoring and studies in mammalian species.

Discussion: In short, our study employed machine learning models to create an important tool for predicting potential hosts of SARS-CoV-2 and achieved the highest precision to our knowledge in experimental validation. This study also predicted that a wide range of mammals were capable of being infected by SARS-CoV-2.
\end{abstract}

\section{INTRODUCTION}

Severe acute respiratory syndrome coronavirus 2 (SARS-CoV-2) has caused the ongoing pandemic of coronavirus disease (COVID-19) and has led to more than 229 million people infected and 4.7 million fatalities as of September 23, 2021 (https://covid19. who.int). Despite a large number of investigations on the biology and pathology of SARS-CoV-2, as well as treatment of COVID-19, the virus and pandemic still pose a tremendous threat to global health and stability. The natural origin of this virus has gained consensus among scientific communities but available evidence is still short of being conclusive. For instance, bats and pangolins have been proposed but disputes still remain (1), leaving room for misinformation and abuse. Identifying the host species susceptible to, including the source and intermediate species of, SARS-CoV-2 is still one of the central scientific objectives for COVID19 research and will help provide information for monitoring and containing a potential viral reservoir as well as preventing reoccurring zoonosis as in the case of influenza viruses.

The entry of SARS-CoV-2 to host cells requires the binding of its spike protein and host angiotensin I converting enzyme 2 (ACE2), a process that underwent intense investigation. Blocking their binding with a list of neutralizing monoclonal antibodies (mAbs) has been demonstrated to effectively prevent viral entry to cells in vitro and in vivo (2), and several $\mathrm{mAbs}$ were approved for clinical treatment of COVID patients (3). Short peptide mimicking the structure of ACE2 region binding to the viral spike protein has also been developed, which binds the receptor binding domain (RBD) of spike proteins with picomole-level affinity and effectiveness in cell assays (4). Besides serving as a target for treatment, the ability of binding between the SARS-CoV-2 spike and the ACE2 from non-human species indicated the susceptibility of those species towards SARS-CoV-2 and, combined with ecological data and evolutionary evidence, might identify key species as probable origins and/or intermediate hosts of SARS-CoV-2.

Screening the binding between the ACE2 from large-scale collection of species and the SARS-CoV-2 spike protein thus is highly desired; however, in reality, 
there are great constraints due to costs and time required for experimental verification. Alternatively, bioinformatic approaches capable of predicting binding between the two proteins with high precision are helpful in prioritizing species of interest and excluding very unlikely species, reducing the cost and time for this purpose. Based on sequence similarity in the ACE2 across species, Damas et al. (5) proposed a score predicting binding to the SARS-CoV-2 spikes; since then, many species' ACE2 have been tested, and retrospectively it is clear that the approach is limited in its precision. Namely, ACE2 from all bat species (36 in total in their prediction) were predicted to be "low" or "very low" in binding to the SARS-CoV-2 spike, but later experiments demonstrated that 20 species' ACE2 $(55.56 \%)$ could bind to the viral spike (G). Alongside bats, 17 out of 29 (58.62\%) other mammals with ACE2 genes considered unlikely to bind to the SARSCoV-2 spike actually had ability to bind as well (Supplementary Table S1, available in http://weekly. chinacdc.cn/). Thus, the currently available bioinformatic approach has an extremely high false negative rate and is still short of precisely predicting binding between the SARS-CoV-2 spike protein and the ACE2 across species.

\section{METHODS}

We have therefore applied machine learning approaches to address the remaining challenges (see Supplementary Materials, available in http://weekly. chinacdc.cn/). Machine learning methods have the ability to combine diverse and complex data and automatically learn features for prediction, classification, and regressions. In biology, they have been successfully applied in establishing predictive and classification models using genomic features ( 7 ), metabolic markers (8), and many more (9). In our study, we selected five representative machine learning methods to perform classification (i.e., prediction of binding vs. non-binding), namely Support Vector Machine (SVM), Decision Tree (DT), Random Forest (RF), Adaboost (ADA), and Gradient Boosting Regression Tree (GBRT). For the single estimator we chose SVM and DT because they are suitable for small training sets. However, single estimators have a tendency to cause poor generalizability or robustness. To reduce this issue, we chose three additional ensemble methods (RF, ADA, and GBRT) for the construction of the prediction model.

The five models were further equipped with a priori information to establish a combined prediction pipeline. A study on the human ACE2 introduced mutations at 117 amino acid (AA) sites individually, whereas at each site the AA was mutated to all potential alternative $A A s$ and the changes in affinity (relative to the wildtype ACE2) to that of SARS-CoV2 have been experimentally examined, providing a quantitative reference data (10). Further, studies from Wang et al. (11) and Liu et al. (12) identified subsets of 24 and 20 AAs, respectively, in the human ACE2 as important sites for interaction with SARS-CoV-2 spike protein, which can be used as qualitative information to reduce model complexity and potential over-fitting. Based on reported experimental verifications of the ACE2 protein from 90 species (73 unique species, 27 from $\mathrm{Wu}$ et al. (13), 49 from Liu et al. (12). 14 are from our lab and currently being considered for independent publication), we aligned the ACE2 sequences of those species to the human ACE2 and extracted AAs to replace with $\log 2$ enrichment ratios for the 117, 24, and 20 sites as input data format (Figure 1A). We have deposited this pipeline and details of the method at https://github.com/mayuefine/ Binding-prediction.

\section{RESULTS}

The training and the test set data contained 62 and 11 species, respectively, and the test set was set aside from the training process. In order to screen the models with a stable performance, we trained five models on three groups of site information (group 20, group 24, and group 117, each group containing 5 machine learning approaches). Finally, the predictions of the three groups were combined and a combination of six models with the highest precision was chosen as our prediction pipeline, out of a total of 408 combinations; this pipeline reached an in silico precision of circa $87.5 \%$ (Figure 1B) and was used for subsequent analysis. We used this pipeline to generate a prediction score for each ACE2 sequence, which was equal to the number of models predicting that it binded to the viral spike divided by the total number of models.

Bat species of the order Chiroptera were of highest interest for tracing the origin and studying the host range of SARS-CoV-2, as bat species harbor multiple coronavirus species including the SARS virus. One of the closest related strains of coronavirus to SARS-CoV2, RaTG13, was found in horseshoe bats (Rhinolophus affinis) (14). Thus, we applied our pipeline and 
(A)

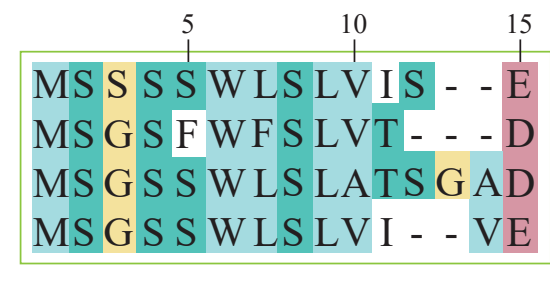

Multiple Sequence Alignment

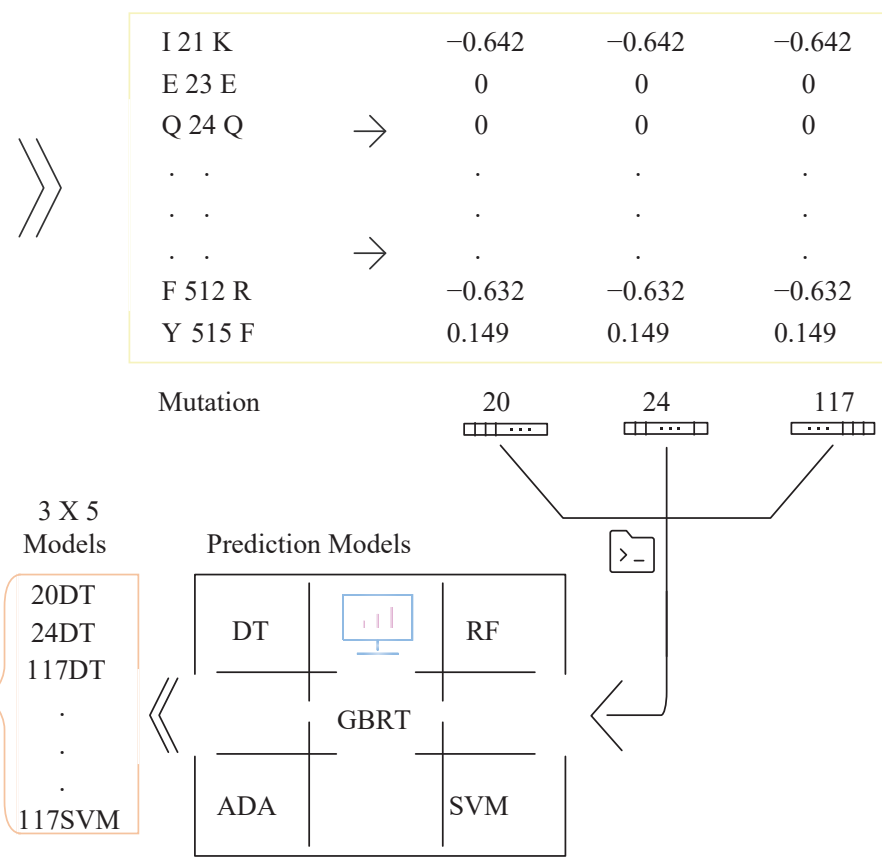

(B)

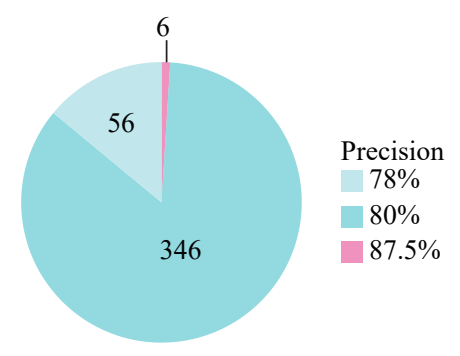

(C)

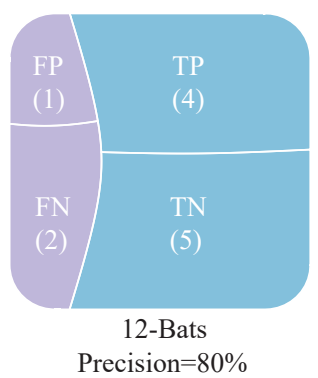

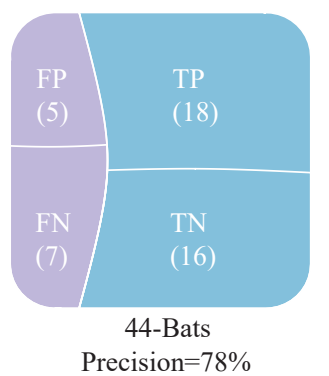

(D)

$\begin{array}{ccccccccccccccccccccccccccccc}\text { Sites } & 212 & 219 & 220 & 221 & 223 & 224 & 225 & 226 & 227 & 228 & 229 & 230 & 231 & 232 & 251 & 630 & 647 & 649 & 694 & 703 & 732 & 733 \\ \text { Homosapiens } & \mathrm{V} & \mathrm{R} & \mathrm{G} & \mathrm{Q} & \mathrm{I} & \mathrm{E} & \mathrm{D} & \mathrm{V} & \mathrm{E} & \mathrm{H} & \mathrm{T} & \mathrm{F} & \mathrm{E} & \mathrm{E} & \mathrm{A} & \mathrm{D} & \mathrm{V} & \mathrm{Y} & \mathrm{I} & \mathrm{A} & \mathrm{G} & \mathrm{P} \\ \text { PteropusAlecto } & \mathrm{I} & \mathrm{R} & \mathrm{D} & \mathrm{Q} & \mathrm{I} & \mathrm{E} & \mathrm{D} & \mathrm{V} & \mathrm{D} & \mathrm{R} & \mathrm{T} & \mathrm{F} & \mathrm{A} & \mathrm{E} & \mathrm{V} & \mathrm{E} & \mathrm{V} & \mathrm{F} & \mathrm{I} & \mathrm{G} & \mathrm{G} & \mathrm{T} \\ \text { Pteropus vampyrus } & \mathrm{T} & - & \mathrm{P} & \mathrm{S} & \mathrm{G} & \mathrm{L} & \mathrm{K} & \mathrm{L} & \mathrm{S} & \mathrm{S} & \mathrm{W} & \mathrm{A} & \mathrm{F} & \mathrm{Q} & \mathrm{A} & \mathrm{D} & \mathrm{I} & \mathrm{Y} & \mathrm{F} & \mathrm{A} & \mathrm{E} & \mathrm{P}\end{array}$

FIGURE 1. Overview of methodology and model performance of this study. (A) Schematic representation of the workflow; (B) The distribution of precision from all 408 potential combinations of models/input data; (C) Distribution of true positive (TP), true negative (TN), false positive (FP), and false negative (FN) in our models' prediction in two experimentally validated datasets; (D) Distribution of different AAs in human (Homo sapiens) and two bat species ( $P$. alecto and $P$. vampyrus).

Note: After sequencing alignment, information from chosen sites were transformed into vectors and fed to five different models, from which the optimal combination was chosen as pipeline and used to predict available ACE2 sequences. After the prediction, we selected some of the sequences for experimental validation. Figure 1B showed that multiple combinations reached high precision using our testing dataset. that we presume to influence binding between ACE2 and viral spike protein as well, based on the observation that the two bat species' ACE2 have different binding with the viral spike.

Abbreviations: ACE2=angiotensin I converting enzyme 2; DT=decision tree; RF=random forest; GBRT=gradient boosting

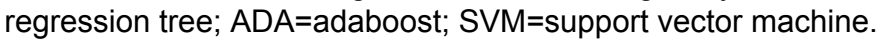

examined across bat species with ACE2 sequences available (59 in total), in which we predicted their ability to bind with SARS-CoV-2 spike proteins. We then tested the precision of our prediction in two experimentally validated datasets, in which ACE2 with predictions score $>0.5$ were considered likely to bind to the viral spike. We selected 12 bats' ACE2 and expressed the proteins, then confirmed with Surface Plasmon Resonance (SPR) and flow cytometry for the ability to bind the viral spike (Supplementary 
(A)

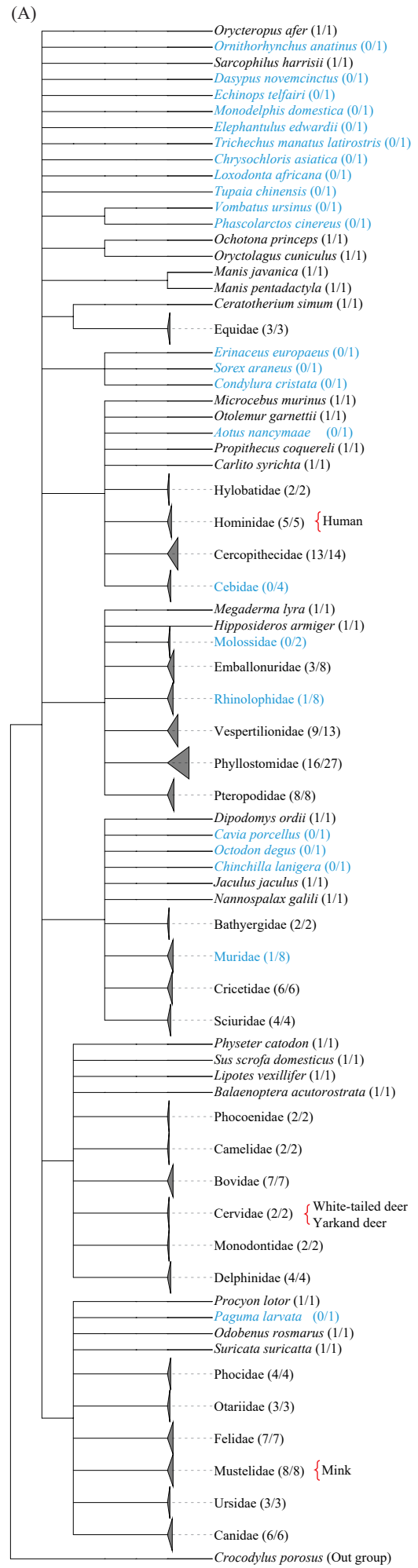

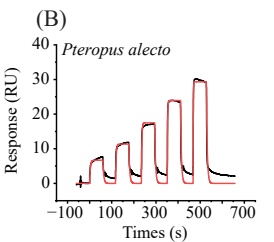
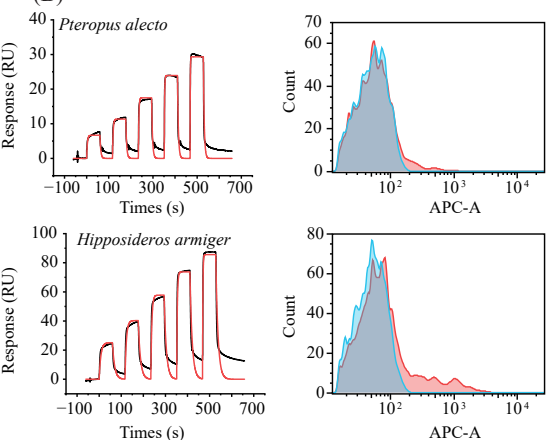

| Perissodactyla

Eulipotyphla
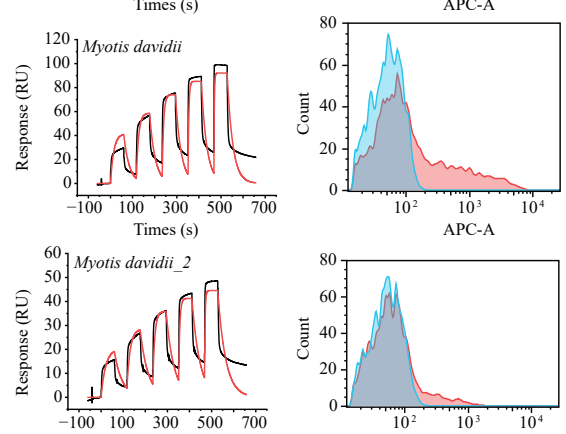

Chiroptera

Times (s)
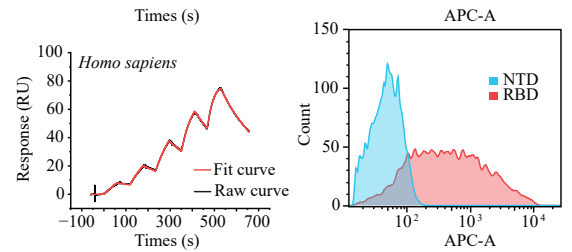

Rodentia

(C)

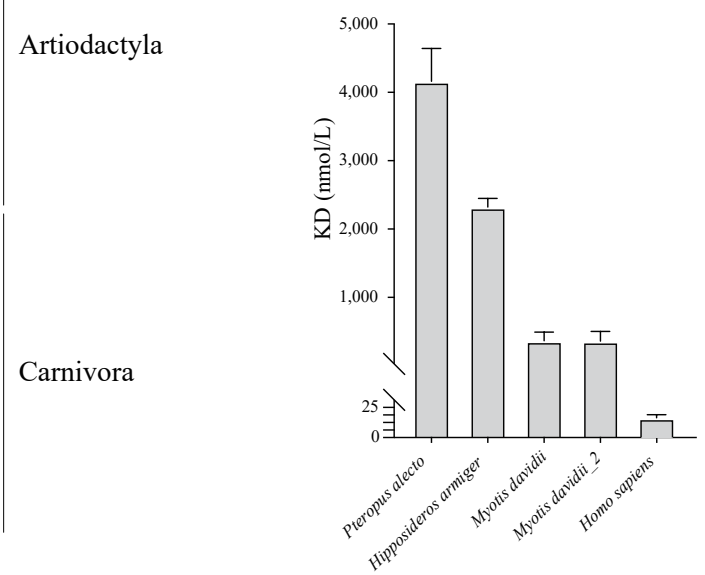

FIGURE 2. Prediction and validations of ACE2 across species in binding to SARS-CoV-2 spike. (A) The predicted range of species with ACE2 capable of binding to SARS-CoV-2; (B) SPR and flow cytometry validation for multiple species' ACE2 in binding to SARS-CoV-2 spike; (C) KD in nmol/L of the species shown in (B).

Note: For families with multiple species, the branch is collapsed and the proportion predicted to bind is shown in Figure $2 \mathrm{~A}$. Blue species/families are those predicted not to bind.

Abbreviations: ACE2=angiotensin I converting enzyme 2; SARS-CoV-2=severe acute respiratory syndrome coronavirus 2; $\mathrm{SPR}=$ surface plasmon resonance; $K D=$ binding affinity. 
Table S2, available in http://weekly.chinacdc.cn/). Overall, 4 of the 6 ACE2s predicted to bind to the SARS-CoV-2spike werevalidated to bind to the viral spike (Figure 2B and Supplementary Figure S1, available in http://weekly.chinacdc.cn/), together with 5 ACE2s confirmed not to bind out of $6 \mathrm{ACE} 2 \mathrm{~s}$ predicted to be so. Here we achieved a precision of $80 \%$ (Figure 1C). Then, using another dataset of 46 bat species by Yan et al. (G), after excluding the 2 sequences contained in our training set, we predicted the binding capacity and achieved $78.26 \%$ precision as shown in Figure 1C. Thus, our unified pipeline incorporating multiple machine learning models and different sets as input has the ability of confidently predicting binding between bat ACE2s and viral spikes.

It also drew our attention that during our validation, ACE2 sequences from Pteropus alecto and Pteropus vampyrus have identical AAs at all 117 sites we selected for input; however, $P$. alecto ACE2 could bind to the SARS-CoV-2 spike in our experimental system and $P$. vampyrus ACE2 had no detectable binding, suggesting additional AAs affected the binding capacity. We compared ACE2 sequences of these 2 species and identified in total 22 sites of difference between the 2 . Of these sites, 16 are identical to human ACE2 (12 for $P$. alecto and 4 for $P$. vampyrus) (Figure $1 \mathrm{D}$ and Figure 2C). This comparison provided extra information that one or more of the AAs different between $P$. alecto and $P$. vampyrus and humans underly the differences in binding to the viral spike protein but have not been discovered in available studies. Closer investigations revealed that this set of AAs was not involved in binding with viral spike protein, thus their influences were indirect and likely affected by the ACE2 protein structurally or even by post-translation modifications including glycosylation.

Eventually, we refined our models incorporating the modified list of AAs as an input, and performed predictions on available ACE2 sequences from mammalian species (Supplementary Table S3, available in http://weekly.chinacdc.cn/, 204 in total and belonging to 69 families). This has resulted in the ACE2 of interest (likely to bind to the SARS-CoV-2 spike) from a total of 144 species, spread across 47 families $(60.87 \%$, Figure $2 \mathrm{~A})$. It is worth noting that the wide range of potential mammalian hosts agree with the emerging evidences of SARS-CoV-2 virus presence across mammals. Aside from 5 species of Hominidae (primates), ACE2s were predicted to bind to the viral spike protein in: 13 species of Cercopithecidae (old world monkeys), 8 species of
Pteropodidae (old world fruit bats), 7 species of Felidae (cats), 7 species of Bovidae (ruminants), 7 species of Mustelidae (containing minks), 6 species of Canidae (dogs), 3 species of Equidae (horses), 6 species of Cricetidae (muroid rodents), 4 species of Sciuridae (squirrels), and 3 species of Ursidae (bears). Even in all 3 families of marine mammal, their ACE2s had high likelihood to bind to the SARS-CoV-2 spike (in all 4 species of Phocidae, 4 of Delphinidae and 3 of Otariidae, Figure 2B). Our prediction was supported by emerging reports that white-tailed deer (family Cervidae) were positive in antibodies against SARSCoV-2 in 2021, which came in addition to reports of dogs, cats, and minks being viable hosts for this virus. In summary, based on ACE2 sequence features, our study suggested that SARS-CoV-2 has an extremely large range of potential hosts and indicates the importance of investigating wild animals for viral existence and monitoring its spread.

\section{DISCUSSION}

In conclusion, our study employed machine learning models suitable for analyzing sequence data, incorporated established functional data with multiple features extracted from sequences, and achieved high precision in predicting binding between ACE2s from difference species to the spike protein of SARS-CoV-2. The precision within the test data set was $87.5 \%$, and in a total of 44 bat species, the group of mammals that attracted most concern, we achieved $>78 \%$ precision as well, indicating that the model can be further expanded to predict susceptibility of more bat species once genomic sequences or ACE2 sequences become available (Supplementary Table S4, available in http://weekly.chinacdc.cn/). With the same approach we have also screened the available ACE2 sequences across a large range of mammals, in which we found that a large range of mammals requires attention. Our pipeline is capable of determining species of interest for tracing and analyzing species of interest to understand the potential origin of and transmission routes of SARS-CoV-2.

Our pipeline, in terms of performance, remains to be improved upon, provided that more accurate machine-learning models and/or more a priori information continues to emerge. First, limited by the number of experimentally validated sets and understanding on ACE2-spike interactions, we had to limit the total AAs in the ACE2 sequences for training and prediction, in which our result already indicated 
contained critical information that is currently unavailable with regard to AAs in other part of the sequence, as in the case of $P$. alecto and $P$. vampyrus. In addition, the growing concerns amid the COVID-19 pandemic lie in the fast-emerging variants of SARSCoV-2 strains, especially when mutations in ACE2interacting $A A s$ in the spike protein have already demonstrated changes in binding affinity to human ACE2s, whether they lead to host range changes and even broader transmission remain to be investigated.

In summary, our approach has the potential and will need to be expanded to analyze binding abilities of different SARS-CoV-2 variants and ACE2s to forecast the potential spread of this virus and identify priority species for monitoring.

Funding: The Strategic Priority Research Programs of the Chinese Academy of Sciences (XDB29020000), the National Natural Science Foundation of China (32041009) and Key R\&D Program of Shandong Province (2020CXGC011305).

doi: $10.46234 / \mathrm{ccdcw} 2021.235$

\# Corresponding authors: Jun Wang, junwang@im.ac.cn; Qihui Wang, wangqihui@im.ac.cn.

${ }^{1}$ CAS Key Laboratory of Pathogen Microbiology and Immunology, Institute of Microbiology, Chinese Academy of Sciences, Beijing, China; ${ }^{2}$ School of Life Sciences, Division of Life Sciences and Medicine, University of Science and Technology of China, Hefei, Anhui, China; ${ }^{3}$ State Key Laboratory for Molecular Virology and Genetic Engineering, National Institute for Viral Disease Control and Prevention, Chinese Center for Disease Control and Prevention, Beijing, China; ${ }^{4}$ Institute of Physical Science and Information, Anhui University, Hefei, Anhui, China; ${ }^{5}$ State Key Laboratory of Virology, Modern Virology Research Center, College of Life Sciences, Wuhan University, Wuhan, Hubei, China.

\& Joint first authors.

Submitted: October 23, 2021; Accepted: November 01, 2021

\section{REFERENCES}

1. Wacharapluesadee S, Tan CW, Maneeorn P, Duengkae P, Zhu F, Joyjinda $\mathrm{Y}$, et al. Evidence for SARS-CoV-2 related coronaviruses circulating in bats and pangolins in Southeast Asia. Nat Commun 2021;12(1):972. http://dx.doi.org/10.1038/s41467-021-21240-1.

2. Kreye J, Reincke SM, Kornau HC, Sánchez-Sendin E, Corman VM,
Liu HJ, et al. A therapeutic non-self-reactive SARS-CoV-2 antibody protects from lung pathology in a COVID-19 hamster model. Cell 2020;183(4):1058 - 69.e19. http://dx.doi.org/10.1016/j.cell.2020.09. 049.

3. U.S. Food \& Drug Administration. Coronavirus (COVID-19) update: FDA authorizes monoclonal antibody for treatment of COVID-19. 2020. https://www.fda.gov/news-events/press-announcements/corona virus-covid-19-update-fda-authorizes-monoclonal-antibody-treatmentcovid-19. [2021-8-22].

4. Cao LX, Goreshnik I, Coventry B, Case JB, Miller L, Kozodoy L, et al. De novo design of picomolar SARS-CoV-2 miniprotein inhibitors. Science 2020;370(6515):426 - 31. http://dx.doi.org/10.1126/science. abd9909.

5. Damas J, Hughes GM, Keough KC, Painter CA, Persky NS, Corbo M, et al. Broad host range of SARS-CoV-2 predicted by comparative and structural analysis of ACE2 in vertebrates. Proc Natl Acad Sci USA 2020;117(36):22311 - 22. http://dx.doi.org/10.1073/pnas.201014 6117.

6. Yan H, Jiao HW, Liu QY, Zhang Z, Xiong Q, Wang BJ, et al. ACE2 receptor usage reveals variation in susceptibility to SARS-CoV and SARS-CoV-2 infection among bat species. Nat Ecol Evol 2021;5(5):600 - 8. http://dx.doi.org/10.1038/s41559-021-01407-1.

7. Huang SJ, Cai NG, Pacheco PP, Narrandes S, Wang Y, Xu W. Applications of support vector machine (SVM) learning in cancer genomics. Cancer Genomics Proteomics 2018;15(1):41 - 51. http://dx. doi.org/10.21873/cgp. 20063 .

8. Liang L, Rasmussen MLH, Piening B, Shen XT, Chen SJ, Röst H, et al. Metabolic dynamics and prediction of gestational age and time to delivery in pregnant women. Cell 2020;181(7):1680 - 92.e15. http:// dx.doi.org/10.1016/j.cell.2020.05.002.

9. Toth R, Schiffmann H, Hube-Magg C, Büscheck F, Höflmayer D, Weidemann S, et al. Random forest-based modelling to detect biomarkers for prostate cancer progression. Clin Epigenetics 2019;11(1):148. http://dx.doi.org/10.1186/s13148-019-0736-8.

10. Chan KK, Dorosky D, Sharma P, Abbasi SA, Dye JM, Kranz DM, et al. Engineering human ACE2 to optimize binding to the spike protein of SARS coronavirus 2. Science 2020;369(6508):1261 - 5. http://dx. doi.org/10.1126/science.abc0870.

11. Wang QH, Zhang YF, Wu LL, Niu S, Song CL, Zhang ZY, et al. Structural and functional basis of SARS-CoV-2 entry by using human ACE2. Cell 2020;181(4):894 - 904.e9. http://dx.doi.org/10.1016/j. cell.2020.03.045.

12. Liu YH, Hu GW, Wang YY, Ren WL, Zhao XM, Ji FS, et al. Functional and genetic analysis of viral receptor ACE2 orthologs reveals a broad potential host range of SARS-CoV-2. Proc Natl Acad Sci USA 2021;118(12):e2025373118. http://dx.doi.org/10.1073/pnas. 2025373118.

13. Wu LL, Chen Q, Liu KF, Wang J, Han PC, Zhang YF, et al. Broad host range of SARS-CoV-2 and the molecular basis for SARS-CoV-2 binding to cat ACE2. Cell Discov 2020;6:68. http://dx.doi.org/10. 1038/s41421-020-00210-9.

14. Liu KF, Pan XQ, Li LJ, Yu F, Zheng AQ, Du P, et al. Binding and molecular basis of the bat coronavirus RaTG13 virus to ACE2 in humans and other species. Cell 2021;184(13):3438 - 51.e10. http://dx. doi.org/10.1016/j.cell.2021.05.031. 


\title{
Supplementary Material
}

\author{
Method
}

\section{Data Collection}

The 73 species angiotensin I converting enzyme 2 (ACE2) sequences for constructing predictive models and evaluation were collected from published articles (1-2) and unpublished data. Overall, 11 sequences from these 73 were randomly selected as test dataset for model evaluation and were not involved in model training.

The sequences of mammalian ACE2 for prediction were downloaded as of September 22, 2020 with a total of 294 ACE2 sequences of mammalian species from 23 orders being gathered. We performed multiple sequence alignment on collection of 294 sequences with human ACE2 sequence, using software CLUSTAL (version 2.1, Conway Institute, UCD, Dublin, Ireland, parameter "complete multiple alignment") (3), in which sequences with more than 10 consecutive amino acid missing in the head 100 sites were excluded from the subsequent analysis, resulting in 272 ACE2 sequences (204 unique species).

\section{Model Construction and Evaluation}

We selected key amino acid sites and used the $\log 2$ enrichment ratios values from Chan et al. to label the amino acids for each ACE2 sequence (4), with 20, 24, and 117 sites selected from Liu et al. (1), Wang et al. (2), and Chan et al. (4), respectively. The sequences screened for these three sites were divided into a training dataset and a test dataset with an 8:2 ratio and used for training and testing of the model, respectively. As for prediction models, we used five different methods to train three different collections of sites, including support vector machine (SVM), Decision Tree, Random Forest, AdaBoost and Gradient Boosting, resulting in 15 models of input data/methods. After hundreds of epochs of training, random combinations of the 15 models were evaluated based on precision (Precision=TP/(TP+FP), where TP: True Positive, FP: False Positive). We selected six model combinations for ACE2 sequences prediction in the subsequent analysis and set the prediction score (Prediction Score $=\mathrm{Pn} / \mathrm{Mn}$ ), where $\mathrm{Pn}$ indicated the number of one sequence that was predicted to have binding ability and Mn was the total number of models used for prediction. The threshold value for the prediction score was set to 0.5 , i.e., a prediction score $\geq 0.5$ was considered to have the ability to bind with Severe acute respiratory syndrome coronavirus 2 (SARS$\mathrm{CoV}-2)$. The 272 sequences were also screened for sites for binding ability prediction.

Model construction and prediction were carried out based on the scikit-learn module in the Python3 (version 0.22.2, Python Software Foundation, Fredericksburg, VA, USA). The functions used for model training were "svm," "DecisionTreeClassifier," "RandomForestClassifier," "AdaBoostClassifier," and "GradientBoostingClassifier." The parameters used for SVM were: gamma='scale'; class_weight $=\{0: 2\}$; for decision tree classifier were default parameters; for random forest classifier were the following: $\mathrm{n} \_$estimators $=600$, oob_score $=$ True, $\mathrm{n} \_$jobs $=-1$, class_weight $=\{0: 2\}$; for Ada boost classifier were the following: base_estimator=DecisionTreeClassifier (max_depth=2), n_estimators=500; and for gradient boosting classifier were the following: n_estimators=100, learning_rate $=1.0$, max_depth $=1$, random_state $=0$. All details were also available in our github depository.

\section{ACE2 Sequence Acquisition and Gene cloning}

Twelve bat orthologs were randomly selected from the test sets. The full-length coding sequences (accession numbers are shown in Supplementary Table S2) of these orthologs were synthesized and cloned into the pEGFP-N1 vector for flow cytometry (FACS). The extracellular domain of these ACE2 orthologs was fused with the Fc domain of mouse IgG $(\mathrm{mFc})$ and cloned into the pCAGGS expression vector for surface plasmon resonance (SPR).

\section{Protein Expression and Purification}

The SARS-CoV-2 receptor-binding domain (RBD) and SARS-CoV-2 N-terminal domain (NTD) proteins used for flow cytometry and SPR were expressed and purified from the supernatants of HEK293F cells culture as described in our previous work (5). Proteins were stored in a PBS buffer $\left[1.8 \mathrm{mmol} / \mathrm{L} \mathrm{KH}_{2} \mathrm{PO}_{4}, 10 \mathrm{mmol} / \mathrm{L}\right.$ $\mathrm{Na}_{2} \mathrm{HPO}_{4}(\mathrm{pH} 7.4), 137 \mathrm{mmol} / \mathrm{L} \mathrm{NaCl}, 2.7 \mathrm{mmol} / \mathrm{L} \mathrm{KCl}$ ) buffer. The indicated pCAGGS plasmids were transiently transfected into HEK293T cells (ATCC CRL-3216). Supernatants containing mFc-tagged ACE2 proteins were collected and concentrated at $48 \mathrm{~h}$ post-transfection. 
SUPPLEMENTARY TABLE S1. Binding ability of various mammalian ACE2, including published experimental results, prediction from Damas et al. (7) using our method.

\begin{tabular}{|c|c|c|c|c|c|c|}
\hline Mammals & Species & Common name & $\begin{array}{l}\text { Experiment } \\
\text { results }\end{array}$ & $\begin{array}{c}\text { Previous prediction } \\
\text { results }\end{array}$ & $\begin{array}{c}\text { Our } \\
\text { prediction }\end{array}$ & Accession Number \\
\hline \multirow{20}{*}{ Bats } & Anoura caudifer & Tailed tailless bat & Binding & Very low & Binding & GCA_004027475.1 \\
\hline & Artibeus jamaicensis & $\begin{array}{l}\text { Jamaican fruit-eating } \\
\text { bat }\end{array}$ & Binding & Very low & Binding & GCA_004027435.1 \\
\hline & Carollia perspicillata & Seba's short-tailed bat & Binding & Very low & Not bind & GCA_004027735.1 \\
\hline & Desmodus rotundus & Common vampire bat & Binding & Very low & Not bind & XP_024425698.1 \\
\hline & Eidolon helvum & Straw-colored fruit bat & Binding & Low & Binding & GCA_000465285.1 \\
\hline & Eonycteris spelaea & Lesser dawn bat & Binding & Low & Binding & GCA_003508835.1 \\
\hline & Macroglossus sobrinus & Long-tongued fruit bat & Binding & Very low & Binding & GCA_004027375.1 \\
\hline & Megaderma lyra & Indian false vampire & Binding & Low & Binding & MT515624 \\
\hline & Micronycteris hirsuta & Hairy big-eared bat & Binding & Very low & Not bind & GCA_004026765.1 \\
\hline & Miniopterus schreibersii & $\begin{array}{l}\text { Schreibers' long- } \\
\text { fingered bat }\end{array}$ & Binding & Very low & Binding & GCA_004026525.1 \\
\hline & Mormoops blainvillei & $\begin{array}{l}\text { Antillean ghost-faced } \\
\text { bat }\end{array}$ & Binding & Very low & Not bind & GCA_004026545.1 \\
\hline & Myotis brandtii & Brandt's bat & Binding & Very low & Binding & XP_014399780.1 \\
\hline & Myotis davidii & David's myotis & Binding & Very low & Binding & XP_006775273.1 \\
\hline & Myotis lucifugus & Little brown bat & Binding & Very low & Binding & XP_023609437.1 \\
\hline & Myotis myotis & $\begin{array}{l}\text { Greater mouse-eared } \\
\text { bat }\end{array}$ & Binding & Very low & Binding & $\begin{array}{l}\text { https://vgp.github.io/geno } \\
\text { meark/Myotis_myotis }\end{array}$ \\
\hline & Noctilio leporinus & Greater bulldog bat & Binding & Very low & Binding & GCA_004026585.1 \\
\hline & Pipistrellus pipistrellus & Common pipistrelle & Binding & Very low & Not bind & GCA_004026625.1 \\
\hline & Pteropus alecto & Black flying fox & Binding & Low & Binding & XP_006911709.1 \\
\hline & Rousettus aegyptiacus & Egyptian rousette & Binding & Low & Binding & XP_015974412.1 \\
\hline & Tadarida brasiliensis & Brazilian free-tailed bat & Binding & Very low & Not bind & GCA_004025005.1 \\
\hline \multirow{17}{*}{$\begin{array}{l}\text { Other } \\
\text { Mammals }\end{array}$} & Ailuropoda melanoleuca & Giant panda & Binding & Low & Binding & XP_002930657.1 \\
\hline & Camelus ferus & Wild Bactrian camel & Binding & Low & Binding & XP_006194263.1 \\
\hline & $\begin{array}{l}\text { Ceratotherium simum } \\
\text { simum }\end{array}$ & $\begin{array}{l}\text { Southern white } \\
\text { rhinoceros }\end{array}$ & Binding & Low & Binding & XP_004435206.1 \\
\hline & Equus caballus & Horse & Binding & Low & Binding & XP_001490241.1 \\
\hline & Peromyscus leucopus & White-footed mouse & Binding & Low & Binding & XP_028743609.1 \\
\hline & Rousettus aegyptiacus & Egyptian rousette & Binding & Low & Binding & XP_015974412.1 \\
\hline & Sus scrofa & Pig & Binding & Low & Binding & NP_001116542.1 \\
\hline & Ursus arctos horribilis & Grizzly bear & Binding & Low & Binding & XP_026333865.1 \\
\hline & Vulpes vulpes & Red fox & Binding & Low & Binding & XP_025842512.1 \\
\hline & Callorhinus ursinus & Northern fur seal & Binding & Very low & Binding & XP_025713397.1 \\
\hline & Eumetopias jubatus & Steller sea lion & Binding & Very low & Binding & XP_027970822.1 \\
\hline & Jaculus jaculus & lesser Egyptian jerboa & Binding & Very low & Binding & XP_004671523.1 \\
\hline & Manis javanica & Malayan pangolin & Binding & Very low & Binding & XP_017505746.1 \\
\hline & Mustela erminea & Stoat & Binding & Very low & Binding & XP_032187677.1 \\
\hline & Myotis lucifugus & Little brown bat & Binding & Very low & Binding & XP_023609437.1 \\
\hline & $\begin{array}{l}\text { Neomonachus } \\
\text { schauinslandi }\end{array}$ & Hawaiian monk seal & Binding & Very low & Binding & XP_021536480.1 \\
\hline & Zalophus californianus & California sea lion & Binding & Very low & Binding & XP_027465353.1 \\
\hline
\end{tabular}

Abbreviations: ACE2=angiotensin I converting enzyme 2. 
SUPPLEMENTARY TABLE S2. Results of binding between ACE2 from 12 bat species and SARS-CoV-2 spike performed in our study.

\begin{tabular}{lccc}
\hline \multicolumn{1}{c}{ Species } & KD (nmol/L) & Prediction score & Accession number \\
\hline Pteropus alecto & $4,163.47 \pm 479.62$ & 1.00 & XP_006911709.1 \\
Pteropus vampyrus & $-^{*}$ & 1.00 & XP_011361275.1 \\
Hipposideros armiger & $2,323.89 \pm 124.60$ & 0.70 & XP_019522936.1 \\
Myotis davidii & $369.03 \pm 126.37$ & 0.79 & XP_015426919.1 \\
Myotis davidii & $361.33 \pm 144.51$ & 0.79 & XP_006775273.1 \\
Rhinolophus pearsonii & - & 0.20 & ABU54053.1 \\
Megaderma lyra & $735.58 \pm 121.91$ & 0.47 & QKE499998.1 \\
Molossus molossus & - & 0.33 & KAF6491643.1 \\
Pipistrellus abramus & - & 0.11 & ACT66266.1 \\
Rhinolophus landeri & $3,635.83 \pm 156.31$ & 0.01 & ALJ94034.1 \\
Scotophilus dinganii & - & 0.22 & QJF77809.1 \\
Tadarida brasiliensis & - & 0.17 & QLF98520.1 \\
Homo sapiens & $13.28 \pm 2.06$ & 1.00 & NP_00135844.1 \\
\hline Note: Prediction & &
\end{tabular}

Note: Prediction score of $>0.5$ is considered to be able to bind SARS-CoV-2 spike.

Abbreviations: ACE2=angiotensin I converting enzyme 2; SARS-CoV-2=severe acute respiratory syndrome coronavirus 2; KD=binding affinity.

${ }^{*}$ No detected affinity.

\section{Flow Cytometry Analysis}

To test the binding between each of the 12 ACE2s and SARS-CoV-2 RBD, the 12 bat ACE2s fused with eGFP were expressed on the cell surface by transfecting each of the 12 pEGFP-N1-ACE2s plasmids into BHK21 cells (ATCC, ATCC CCL-10) using PEI (Alfa). Cell culture was replaced with fresh media (DMEM with 10\% FBS, Gibco) 4-6 h post-transfection. After $48 \mathrm{~h}$, cells were collected and resuspended in PBS. Then, $2 \times 10^{5}$ cells were incubated with the histidine tagged test proteins (SARS-CoV-2 RBD, SARS-CoV-2 NTD) at a concentration of 10 $\mu \mathrm{g} / \mathrm{mL}$ at $37^{\circ} \mathrm{C}$ for $30 \mathrm{~min}$. Cells were then washed three times in PBS and stained with anti-His/APC antibodies (1:500, Miltenyi Biotec, AB_2751870) for $30 \mathrm{~min}$ at $37^{\circ} \mathrm{C}$. Flow cytometry (FACS) data were acquired on a BD FACSCanto (BD Biosciences, Franklin Lakes, NJ, USA) and analyzed using FlowJo V10 software (TreeStar Inc., Ashland, OR, USA), with results shown in Supplementary Figure S1.

\section{SPR Analysis}

We tested the binding affinities between the mFc-tagged ACE2s and SARS-CoV-2 RBD or SARS-CoV RBD proteins by SPR using a BIAcore $8 \mathrm{~K}$ (GE Healthcare) carried out at $25^{\circ} \mathrm{C}$ in single-cycle mode. The PBST buffer $\left(1.8 \mathrm{mmol} / \mathrm{L} \mathrm{KH}_{2} \mathrm{PO}_{4}, 10 \mathrm{mmol} / \mathrm{L} \mathrm{Na}_{2} \mathrm{HPO}_{4}(\mathrm{pH} 7.4), 137 \mathrm{mmol} / \mathrm{L} \mathrm{NaCl}, 2.7 \mathrm{mmol} / \mathrm{L} \mathrm{KCl}\right.$, and 0.05\% (v/v) Tween 20) was used as the running buffer. The CM5 biosensor chip was first immobilized with anti-mIgG antibody (ZSGB-BIO, ZF-0513) as previously described. (1) The supernatants containing mFc-tagged ACE2s were injected and captured by the antibody immobilized on the CM5 chip at approximately 300-600 response units. The serially diluted SARS-CoV-2 RBD protein flowed over the chip surface, with another channel set as control. The chip was regenerated using $\mathrm{pH} 1.7$ glycine after each reaction. The equilibrium dissociation constants (binding affinity, KD) for each pair of interaction were calculated with BIAcore_8K evaluation software (GE Healthcare, Chicago, IL, USA) by fitting to a 1:1 Langmuir binding model. Data were analyzed using OriginLab (Origin 2018, OriginLab Corporation, Northampton, MA, USA).

\section{Phylogenetic Tree}

The phylogenetic tree was constructed by uploading the species names from 272 sequences into NCBI Taxonomy Common Tree (https://www.ncbi.nlm.nih.gov/Taxonomy/CommonTree/). The visualization of the phylogenetic tree was based on iTol (G). 

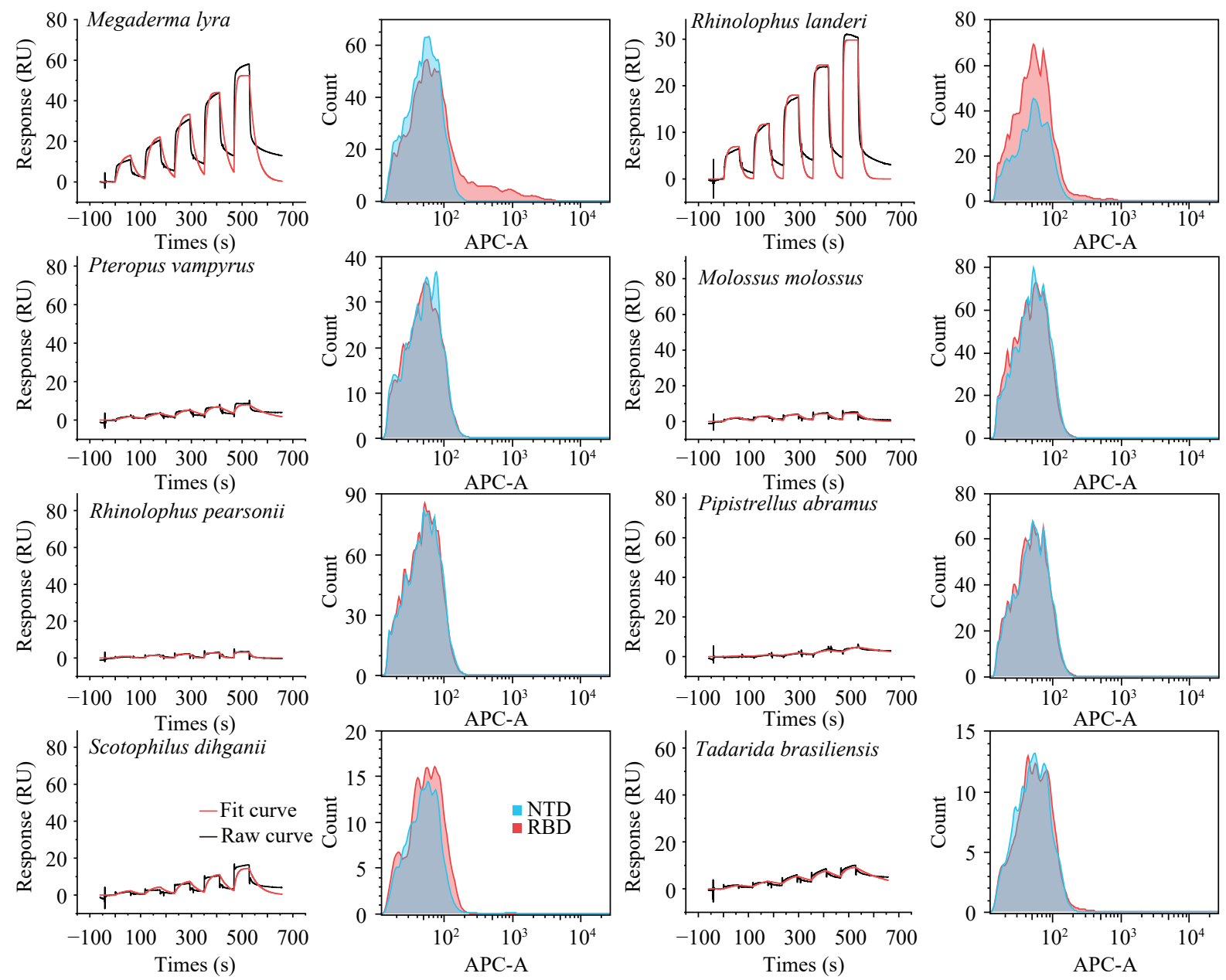

SUPPLEMENTARY FIGURE S1. SPR and flow cytometry validation for multiple species' ACE2.

Abbreviations: ACE2=angiotensin I converting enzyme 2; SPR=surface plasmon resonance; RU=response unit; NTD=Nterminal domain; RBD=receptor-binding domain. 
SUPPLEMENTARY TABLE S3. Prediction of the binding capacity of collected mammalian ACE2 to SARS-CoV-2.

\begin{tabular}{|c|c|c|c|}
\hline Species & Common name & Prediction scores & Data availability \\
\hline Hylobates moloch & Silvery gibbon & 1.00 & XP_032612508.1 \\
\hline Phocoena sinus & Vaquita & 1.00 & XP_032476001.1 \\
\hline Globicephala melas & Long-finned pilot whale & 1.00 & XP_030703991.1 \\
\hline Lynx canadensis & Canada lynx & 1.00 & XP_030160839.1 \\
\hline Monodon monoceros & Narwhal & 1.00 & XP_029095804.1 \\
\hline Peromyscus leucopus & White-footed mouse & 1.00 & XP_028743609.1 \\
\hline Balaenoptera acutorostrata scammoni & Common minke whale & 1.00 & XP_028020351.1 \\
\hline Eumetopias jubatus & Steller sea lion & 1.00 & XP_027970822.1 \\
\hline Marmota flaviventris & Yellow-bellied marmot & 1.00 & XP_027802308.1 \\
\hline Zalophus californianus & California sea lion & 1.00 & XP_027465353.1 \\
\hline Bos indicus $x$ Bos taurus & Hybrid cattle & 1.00 & XP_027389729.1 \\
\hline Bos indicus $x$ Bos taurus & Hybrid cattle & 1.00 & XP_027389727.1 \\
\hline Cricetulus griseus & Chinese hamster & 1.00 & XP_027288607.1 \\
\hline Lagenorhynchus obliquidens & Pacific white-sided dolphin & 1.00 & XP_026951598.1 \\
\hline Acinonyx jubatus & Cheetah & 1.00 & XP_026910297.1 \\
\hline Ursus arctos horribilis & Grizzly bear & 1.00 & XP_026333865.1 \\
\hline Vulpes vulpes & Red fox & 1.00 & XP_025842512.1 \\
\hline Puma concolor & Puma & 1.00 & XP_025790417.1 \\
\hline Callorhinus ursinus & Northern fur seal & 1.00 & XP_025713397.1 \\
\hline Canis lupus dingo & Dingo & 1.00 & XP_025292925.1 \\
\hline Theropithecus gelada & Gelada & 1.00 & XP_025227847.1 \\
\hline Neophocaena asiaeorientalis asiaeorientalis & Yangtze finless & 1.00 & XP_024599894.1 \\
\hline Pongo abelii & Sumatran orangutan & 1.00 & XP_024096013.1 \\
\hline Physeter catodon & Sperm whale & 1.00 & XP_023971279.1 \\
\hline Felis catus & Domestic cat & 1.00 & XP_023104564.1 \\
\hline Piliocolobus tephrosceles & Ugandan red colobus & 1.00 & XP_023054821.1 \\
\hline Delphinapterus leucas & Beluga whale & 1.00 & XP_022418360.1 \\
\hline Papio anubis & Olive baboon & 1.00 & XP_021788732.1 \\
\hline Neomonachus schauinslandi & Hawaiian monk seal & 1.00 & XP_021536486.1 \\
\hline Neomonachus schauinslandi & Hawaiian monk seal & 1.00 & XP_021536480.1 \\
\hline Sus scrofa & Pig & 1.00 & XP_020935034.1 \\
\hline Sus scrofa & Pig & 1.00 & XP_020935033.1 \\
\hline Odocoileus virginianus texanus & White-tailed deer & 1.00 & XP_020768965.1 \\
\hline Bos indicus & Bos taurus indicus & 1.00 & XP_019811720.1 \\
\hline Bos indicus & Bos taurus indicus & 1.00 & XP_019811719.1 \\
\hline Tursiops truncatus & Common bottlenose dolphin & 1.00 & XP_019781177.1 \\
\hline Panthera pardus & Leopard & 1.00 & XP_019273508.1 \\
\hline Gorilla gorilla gorilla & Western lowland gorilla & 1.00 & XP_018874749.1 \\
\hline Manis javanica & Malayan pangolin & 1.00 & XP_017505746.1 \\
\hline Pan troglodytes & Chimpanzee & 1.00 & XP_016798469.1 \\
\hline Pan troglodytes & Chimpanzee & 1.00 & XP_016798468.1 \\
\hline Rousettus aegyptiacus & Egyptian rousette & 1.00 & XP_015974412.1 \\
\hline
\end{tabular}




\begin{tabular}{|c|c|c|c|}
\hline Species & Common name & Prediction scores & Data availability \\
\hline Marmota marmota marmota & Alpine marmot & 1.00 & XP_015343540.1 \\
\hline Propithecus coquereli & Coquerel's sifaka & 1.00 & XP_012494185.1 \\
\hline Ovis aries & Sheep & 1.00 & XP_011961657.1 \\
\hline Cercocebus atys & Sooty mangabey & 1.00 & XP_011891198.1 \\
\hline Mandrillus leucophaeus & Drill & 1.00 & XP_011850923.1 \\
\hline Colobus angolensis palliatus & Angola colobus & 1.00 & XP_011795654.1 \\
\hline Macaca nemestrina & Pig-tailed macaque & 1.00 & XP_011733505.1 \\
\hline Homo sapiens & Human & 1.00 & XP_011543854.1 \\
\hline Homo sapiens & Human & 1.00 & XP_011543853.1 \\
\hline Homo sapiens & Human & 1.00 & XP_011543851.1 \\
\hline Pteropus vampyrus & Large flying fox & 1.00 & XP_011361275.1 \\
\hline Rhinopithecus roxellana & Golden snub-nosed monkey & 1.00 & XP_010364367.2 \\
\hline Pan paniscus & Pygmy chimpanzee & 1.00 & XP_008972437.1 \\
\hline Pan paniscus & Pygmy chimpanzee & 1.00 & XP_008972428.1 \\
\hline Nannospalax galili & $\begin{array}{l}\text { Upper galilee mountains blind } \\
\text { mole rat }\end{array}$ & 1.00 & XP_008839098.1 \\
\hline Ursus maritimus & Polar bear & 1.00 & XP_008694637.1 \\
\hline Chlorocebus sabaeus & Green monkey & 1.00 & XP_007989304.1 \\
\hline Lipotes vexillifer & Yangtze River dolphin & 1.00 & XP_007466389.1 \\
\hline Panthera tigris altaica & Amur tiger & 1.00 & XP_007090142.1 \\
\hline Peromyscus maniculatus bairdii & Prairie deer mouse & 1.00 & XP_006973269.1 \\
\hline Pteropus alecto & Black flying fox & 1.00 & XP_006911709.1 \\
\hline Bubalus bubalis & Water buffalo & 1.00 & XP_006041602.1 \\
\hline Bos mutus & Wild yak & 1.00 & XP_005903173.1 \\
\hline Capra hircus & Goat & 1.00 & XP_005701129.2 \\
\hline Canis lupus familiaris & Dog & 1.00 & XP_005641049.1 \\
\hline Macaca fascicularis & Crab-eating macaque & 1.00 & XP_005593094.1 \\
\hline Ictidomys tridecemlineatus & Thirteen-lined ground squirrel & 1.00 & XP_005316051.3 \\
\hline Bos taurus & Cattle & 1.00 & XP_005228486.1 \\
\hline Bos taurus & Cattle & 1.00 & XP_005228485.1 \\
\hline Mesocricetus auratus & Golden hamster & 1.00 & XP_005074266.1 \\
\hline Heterocephalus glaber & Naked mole-rat & 1.00 & XP_004866157.1 \\
\hline Ochotona princeps & American pika & 1.00 & XP_004597549.2 \\
\hline Ceratotherium simum simum & Southern white rhinoceros & 1.00 & XP_004435206.1 \\
\hline Odobenus rosmarus divergens & Pacific walrus & 1.00 & XP_004415448.1 \\
\hline Orcinus orca & Killer whale & 1.00 & XP_004269705.1 \\
\hline Cricetulus griseus & Chinese hamster & 1.00 & XP_003503283.1 \\
\hline Nomascus leucogenys & Northern white-cheeked gibbon & 1.00 & XP_003261132.2 \\
\hline Ailuropoda melanoleuca & Giant panda & 1.00 & XP_002930657.1 \\
\hline Oryctolagus cuniculus & Rabbit & 1.00 & XP_002719891.1 \\
\hline Chrysocyon brachyurus & Maned wolf & 1.00 & QNC68917.1 \\
\hline Neofelis diardi & Sunda clouded leopard & 1.00 & QNC68916.1 \\
\hline Speothos venaticus & Bush dog & 1.00 & QNC68915.1 \\
\hline Manis pentadactyla & Chinese pangolin & 1.00 & QLH93383.1 \\
\hline
\end{tabular}


Continued

\begin{tabular}{|c|c|c|c|}
\hline Species & Common name & Prediction scores & Data availability \\
\hline Dobsonia viridis & Greenish naked-backed fruit bat & 1.00 & QJF77815.1 \\
\hline Syconycteris australis & Southern blossom bat & 1.00 & QJF77811.1 \\
\hline Epomophorus wahlbergi & Wahlberg's epauletted fruit bat & 1.00 & QJF77792.1 \\
\hline Homo sapiens & Human & 1.00 & NP_068576.1 \\
\hline Homo sapiens & Human & 1.00 & NP_001358344.1 \\
\hline Capra hircus & Goat & 1.00 & NP_001277036.1 \\
\hline Canis lupus familiaris & Dog & 1.00 & NP_001158732.1 \\
\hline Macaca mulatta & Rhesus monkey & 1.00 & NP_001129168.1 \\
\hline Pongo abelii & Sumatran orangutan & 1.00 & NP_001124604.1 \\
\hline Sus scrofa & Pig & 1.00 & NP_001116542.1 \\
\hline Felis catus & Domestic cat & 1.00 & NP_001034545.1 \\
\hline Bos taurus & Cattle & 1.00 & NP_001019673.2 \\
\hline Rousettus leschenaultii & Leschenault's rousette & 1.00 & BAF50705.1 \\
\hline Rousettus leschenaultii & Leschenault's rousette & 1.00 & ADJ19219.1 \\
\hline Mesocricetus auratus & Golden hamster & 1.00 & АCT66278.1 \\
\hline Felis catus & Domestic cat & 1.00 & АCT66276.1 \\
\hline Oryctolagus cuniculus & Rabbit & 1.00 & АCT66271.1 \\
\hline Sus scrofa domesticus & Domestic pig & 1.00 & АCT66265.1 \\
\hline Rhinolophus ferrumequinum & Greater horseshoe bat & 1.00 & ACM45790.1 \\
\hline Macaca mulatta & Rhesus monkey & 1.00 & $\mathrm{ACl} 04576.1$ \\
\hline Macaca mulatta & Rhesus monkey & 1.00 & ACl04571.1 \\
\hline Macaca mulatta & Rhesus monkey & 1.00 & ACI04570.1 \\
\hline Macaca mulatta & Rhesus monkey & 1.00 & $\mathrm{ACl} 04569.1$ \\
\hline Macaca mulatta & Rhesus monkey & 1.00 & ACl04568.1 \\
\hline Macaca mulatta & Rhesus monkey & 1.00 & ACI04567.1 \\
\hline Macaca mulatta & Rhesus monkey & 1.00 & ACl04566.1 \\
\hline Macaca mulatta & Rhesus monkey & 1.00 & $\mathrm{ACl} 04564.1$ \\
\hline Macaca mulatta & Rhesus monkey & 1.00 & ACI04563.1 \\
\hline Macaca mulatta & Rhesus monkey & 1.00 & ACI04562.1 \\
\hline Macaca mulatta & Rhesus monkey & 1.00 & $\mathrm{ACl} 04560.1$ \\
\hline Macaca mulatta & Rhesus monkey & 1.00 & ACl04559.1 \\
\hline Macaca mulatta & Rhesus monkey & 1.00 & ACI04557.1 \\
\hline Macaca mulatta & Rhesus monkey & 1.00 & ACI04556.1 \\
\hline Macaca mulatta & Rhesus monkey & 1.00 & ACI04555.1 \\
\hline Macaca mulatta & Rhesus monkey & 1.00 & $\mathrm{ACl} 04554.1$ \\
\hline Macaca mulatta & Rhesus monkey & 1.00 & ACl04553.1 \\
\hline Macaca mulatta & Rhesus monkey & 1.00 & $\mathrm{ACI} 04552.1$ \\
\hline Nyctereutes procyonoides & Raccoon dog & 1.00 & ABW16956.1 \\
\hline Chlorocebus aethiops & Grivet & 1.00 & AAY57872.1 \\
\hline Camelus ferus & Wild bactrian camel & 0.99 & XP_006194263.1 \\
\hline Jaculus jaculus & Lesser Egyptian jerboa & 0.99 & XP_004671523.1 \\
\hline Mirounga leonina & Southern elephant seal & 0.97 & XP_034852450.1 \\
\hline Trachypithecus francoisi & Francois's langur & 0.97 & XP_033056809.1 \\
\hline
\end{tabular}




\begin{tabular}{|c|c|c|c|}
\hline Species & Common name & Prediction scores & Data availability \\
\hline Macaca mulatta & Rhesus monkey & 0.97 & ACI04573.1 \\
\hline Equus asinus & African wild ass & 0.93 & XP_014713133.1 \\
\hline Equus przewalskii & Przewalski's horse & 0.93 & XP_008542995.1 \\
\hline Orycteropus afer afer & Aardvark & 0.93 & XP_007951028.1 \\
\hline Microtus ochrogaster & Prairie vole & 0.93 & XP_005358818.1 \\
\hline Equus caballus & Horse & 0.93 & XP_001490241.1 \\
\hline Neovison vison & American mink & 0.93 & QPL12211.1 \\
\hline Arctonyx collaris & Hog badger & 0.93 & QLF98526.1 \\
\hline Cynopterus sphinx & Indian short-nosed fruit bat & 0.93 & QKE49997.1 \\
\hline Uroderma bilobatum & Tent-building bat & 0.93 & QJF77842.1 \\
\hline Platyrrhinus vittatus & Greater broad-nosed bat & 0.93 & QJF77835.1 \\
\hline Platyrrhinus helleri & Heller's broad-nosed bat & 0.93 & QJF77834.1 \\
\hline Cynopterus sphinx & Indian short-nosed fruit bat & 0.93 & QJF77831.1 \\
\hline Chiroderma villosum & Hairy big-eyed bat & 0.93 & QJF77830.1 \\
\hline Chiroderma salvini & Salvin's big-eyed bat & 0.93 & QJF77829.1 \\
\hline Artibeus phaeotis & Dwarf fruit-eating bat & 0.93 & QJF77823.1 \\
\hline Artibeus lituratus & Great fruit-eating bat & 0.93 & QJF77822.1 \\
\hline Artibeus jamaicensis & Jamaican fruit-eating bat & 0.93 & QJF77821.1 \\
\hline Phodopus campbelli & Campbell's desert hamster & 0.93 & АCT66274.1 \\
\hline Fukomys damarensis & Damara mole-rat & 0.91 & XP_010643477.1 \\
\hline Cervus hanglu yarkandensis & Yarkand deer & 0.88 & KAF4027296.1 \\
\hline Urocitellus parryii & Arctic ground squirrel & 0.87 & XP_026252506.1 \\
\hline Urocitellus parryii & Arctic ground squirrel & 0.87 & XP_026252505.1 \\
\hline Myotis lucifugus & Little brown bat & 0.87 & XP_023609439.1 \\
\hline Myotis lucifugus & Little brown bat & 0.87 & XP_023609437.1 \\
\hline Myotis brandtii & Brandt's bat & 0.87 & XP_014399783.1 \\
\hline Myotis brandtii & Brandt's bat & 0.87 & XP_014399782.1 \\
\hline Myotis brandtii & Brandt's bat & 0.87 & XP_014399780.1 \\
\hline Taphozous melanopogon & Black-bearded Tomb Bat & 0.87 & QJF77841.1 \\
\hline Taphozous theobaldi & Theobald's tomb bat & 0.87 & QJF77840.1 \\
\hline Artibeus glaucus watsoni & $-{ }^{*}$ & 0.87 & QJF77824.1 \\
\hline Artibeus hartii & Little fruit-eating bat & 0.86 & QJF77832.1 \\
\hline Scotophilus kuhlii & Lesser asiatic yellow house bat & 0.82 & QJF77810.1 \\
\hline Scotophilus dinganii & Yellow-bellied house bat & 0.82 & QJF77809.1 \\
\hline Procyon lotor & Raccoon & 0.80 & BAE72462.1 \\
\hline Myotis davidii & David's myotis & 0.79 & XP_015426919.1 \\
\hline Myotis davidii & David's myotis & 0.79 & XP_006775273.1 \\
\hline Tylonycteris robustula & Greater bamboo bat & 0.79 & QJF77813.1 \\
\hline Sarcophilus harrisii & Tasmanian devil & 0.77 & XP_031814825.1 \\
\hline Dipodomys ordii & Ord's kangaroo rat & 0.77 & XP_012887573.1 \\
\hline Dipodomys ordii & Ord's kangaroo rat & 0.77 & XP_012887572.1 \\
\hline Vicugna pacos & Alpaca & 0.77 & XP_006212709.1 \\
\hline Phoca vitulina & Harbor seal & 0.73 & XP_032245506.1 \\
\hline
\end{tabular}




\begin{tabular}{|c|c|c|c|}
\hline Species & Common name & Prediction scores & Data availability \\
\hline Eptesicus fuscus & Big brown bat & 0.73 & XP_027986092.1 \\
\hline Eptesicus fuscus & Big brown bat & 0.73 & XP_008153150.1 \\
\hline Megaderma lyra & Indian false vampire & 0.73 & QKE49998.1 \\
\hline Hipposideros armiger & Great roundleaf bat & 0.70 & XP_019522936.1 \\
\hline Glossophaga commissarisi & Commissaris's long-tongued bat & 0.70 & QJF77793.1 \\
\hline Microcebus murinus & Gray mouse lemur & 0.69 & XP_020140826.1 \\
\hline Carlito syrichta & Philippine tarsier & 0.69 & XP_008062810.1 \\
\hline Anoura geoffroyi & Geoffroy's tailless bat & 0.67 & QJF77820.1 \\
\hline Suricata suricatta & Meerkat & 0.66 & XP_029786256.1 \\
\hline Anoura cultrata & Handley's tailless bat & 0.66 & QJF77819.1 \\
\hline Kerivoula pellucida & Clear-winged woolly bat & 0.63 & QJF77795.1 \\
\hline Grammomys surdaster & Grammomys & 0.60 & XP_028617961.1 \\
\hline Coleura afra & African sheath-tailed bat & 0.59 & QJF77826.1 \\
\hline Neoromicia nanus & Banana bat & 0.58 & QJF77804.1 \\
\hline Otolemur garnettii & Small-eared galago & 0.56 & XP_003791912.1 \\
\hline Hylonycteris underwoodi & Underwood's long-tongued bat & 0.54 & QJF77833.1 \\
\hline Lontra canadensis & Northern American river otter & 0.53 & XP_032736028.1 \\
\hline Enhydra lutris kenyoni & Sea otter & 0.53 & XP_022374079.1 \\
\hline Enhydra lutris kenyoni & Sea otter & 0.53 & XP_022374078.1 \\
\hline Mustela lutreola & European mink & 0.53 & QNC68911.1 \\
\hline Melogale moschata & Chinese ferret-badger & 0.53 & QLF98521.1 \\
\hline Mustela putorius furo & Domestic ferret & 0.53 & NP_001297119.1 \\
\hline Mustela erminea & Stoat & 0.53 & XP_032187677.1 \\
\hline Halichoerus grypus & Gray seal & 0.52 & XP_035963182.1 \\
\hline Sturnira parvidens & - & 0.51 & QJF77839.1 \\
\hline Sturnira ludovici & Highland Yellow-shouldered Bat & 0.51 & QJF77838.1 \\
\hline Sturnira hondurensis & - & 0.51 & QJF77837.1 \\
\hline Arvicanthis niloticus & African grass rat & 0.49 & XP_034341939.1 \\
\hline Mastomys coucha & Southern multimammate mouse & 0.47 & XP_031226742.1 \\
\hline Mus pahari & Shrew mouse & 0.47 & XP_021043935.1 \\
\hline Antrozous pallidus & Pallid bat & 0.47 & QJF77789.1 \\
\hline Carollia perspicillata & Seba's short-tailed bat & 0.44 & QJF77828.1 \\
\hline Carollia castanea & Chestnut short-tailed bat & 0.44 & QJF77827.1 \\
\hline Chinchilla lanigera & Long-tailed chinchilla & 0.42 & XP_013362428.1 \\
\hline Chinchilla lanigera & Long-tailed chinchilla & 0.42 & NP_001269290.1 \\
\hline Rhinolophus sinicus & Chinese rufous horseshoe bat & 0.41 & АСТ66275.1 \\
\hline Mus caroli & Ryukyu mouse & 0.40 & XP_021009138.1 \\
\hline Vampyrum spectrum & Spectral bat & 0.38 & QJF77843.1 \\
\hline Carollia sowelli & Sowell's short-tailed bat & 0.38 & QJF77814.1 \\
\hline Loxodonta africana & African savanna elephant & 0.37 & XP_023410960.1 \\
\hline Tadarida brasiliensis & Brazilian free-tailed bat & 0.37 & QLF98520.1 \\
\hline Sorex araneus & European shrew & 0.36 & XP_004612266.1 \\
\hline Elephantulus edwardii & Cape elephant shrew & 0.34 & XP_006892457.1 \\
\hline
\end{tabular}


Continued

\begin{tabular}{|c|c|c|c|}
\hline Species & Common name & Prediction scores & Data availability \\
\hline Rattus norvegicus & Norway rat & 0.34 & NP_001012006.1 \\
\hline Molossus molossus & Pallas's mastiff bat & 0.33 & KAF6491643.1 \\
\hline Aeorestes cinereus & Hoary bat & 0.33 & QJF77796.1 \\
\hline Cavia porcellus & Domestic guinea pig & 0.32 & АСТ66270.1 \\
\hline Rhinolophus sinicus & Chinese rufous horseshoe bat & 0.31 & ADN93475.1 \\
\hline Micronycteris schmidtorum & Schmidts's big-eared bat & 0.26 & QJF77799.1 \\
\hline Lonchophylla robusta & Orange nectar bat & 0.24 & QJF77797.1 \\
\hline Glossophaga soricina & Pallas's long-tongued bat & 0.24 & QJF77794.1 \\
\hline Miniopterus natalensis & Natal long-fingered bat & 0.22 & XP_016058453.1 \\
\hline Tupaia chinensis & Chinese tree shrew & 0.22 & XP_006164754.1 \\
\hline Dasypus novemcinctus & Nine-banded armadillo & 0.22 & XP_004449124.1 \\
\hline Rhinolophus macrotis & Big-eared horseshoe bat & 0.22 & ADN93471.1 \\
\hline Sapajus apella & Tufted capuchin & 0.20 & XP_032141854.1 \\
\hline Cebus capucinus imitator & White headed capuchin & 0.20 & XP_017367865.1 \\
\hline Condylura cristata & Star-nosed mole & 0.20 & XP_012585871.1 \\
\hline Aotus nancymaae & Ma's night monkey & 0.20 & XP_012290105.1 \\
\hline Saimiri boliviensis boliviensis & Bolivian squirrel monkey & 0.20 & XP_010334925.1 \\
\hline Callithrix jacchus & White-tufted-ear marmoset & 0.20 & XP_008987241.1 \\
\hline Emballonura alecto & Small Asian sheath-tailed bat & 0.20 & QJF77816.1 \\
\hline Mus musculus & House mouse & 0.20 & NP_001123985.1 \\
\hline Mus musculus & House mouse & 0.20 & АСТ66269.1 \\
\hline Rhinolophus pearsonii & Pearson's horseshoe bat & 0.20 & ABU54053.1 \\
\hline Vombatus ursinus & Common wombat & 0.19 & XP_027691156.1 \\
\hline Phascolarctos cinereus & Koala & 0.19 & XP_020863153.1 \\
\hline Grammomys surdaster & Grammomys & 0.18 & XP_028636273.1 \\
\hline Mirounga leonina & Southern elephant seal & 0.17 & XP_034882212.1 \\
\hline Phoca vitulina & Harbor seal & 0.17 & XP_032285427.1 \\
\hline Octodon degus & Degu & 0.17 & XP_023569950.1 \\
\hline Monodelphis domestica & Gray short-tailed opossum & 0.17 & XP_007500942.1 \\
\hline Monodelphis domestica & Gray short-tailed opossum & 0.17 & XP_007500941.1 \\
\hline Monodelphis domestica & Gray short-tailed opossum & 0.17 & XP_007500935.1 \\
\hline Paguma larvata & Masked palm civet & 0.17 & Q56NL1.1 \\
\hline Phyllostomus discolor & Pale spear-nosed bat & 0.16 & XP_028378317.1 \\
\hline Desmodus rotundus & Common vampire bat & 0.16 & XP_024425698.1 \\
\hline Rhynchonycteris naso & Proboscis bat & 0.16 & QJF77807.1 \\
\hline Octodon degus & Degu & 0.14 & XP_023575315.1 \\
\hline Trichechus manatus latirostris & Florida manatee & 0.13 & XP_004386381.1 \\
\hline Rhinolophus alcyone & Halcyon horseshoe bat & 0.13 & ALJ94035.1 \\
\hline Cavia porcellus & Domestic guinea pig & 0.12 & XP_023417808.1 \\
\hline Pipistrellus abramus & Japanese house bat & 0.11 & АСТ66266.1 \\
\hline Theropithecus gelada & Gelada & 0.10 & XP_025218729.1 \\
\hline Chrysochloris asiatica & Cape golden mole & 0.10 & XP_006833624.1 \\
\hline Micronycteris hirsuta & Hairy big-eared bat & 0.10 & QJF77798.1 \\
\hline
\end{tabular}


Continued

\begin{tabular}{llcc}
\hline \multicolumn{1}{c}{ Species } & \multicolumn{1}{c}{ Common name } & Prediction scores & Data availability \\
\hline Crocodylus porosus & Australian saltwater crocodile & 0.09 & XP_019384827.1 \\
Crocodylus porosus & Australian saltwater crocodile & 0.09 & XP_019384826.1 \\
Ornithorhynchus anatinus & Platypus & 0.08 & XP_001515597.2 \\
Micronycteris microtis & Common big-eared bat & 0.08 & QJF77800.1 \\
Chrysochloris asiatica & Cape golden mole & 0.07 & XP_006835673.1 \\
Centronycteris centralis & Thomas's shaggy bat & 0.07 & QJF77790.1 \\
Rhinolophus sinicus & Chinese rufous horseshoe bat & 0.07 & ADN93472.1 \\
Balantiopteryx plicata & Gray sac-winged rat & 0.03 & QJF77825.1 \\
Echinops telfairi & Small madagascar hedgehog & 0.01 & XP_004710002.1 \\
Rhinolophus landeri & Lander's horseshoe bat & 0.01 & ALJ94034.1 \\
Rhinolophus pusillus & Least horseshoe bat & 0.01 & ADN93477.1 \\
Erinaceus europaeus & Western European hedgehog & 0.00 & XP_007538670.1 \\
Saccopteryx bilineata & Greater sac-winged bat & 0.00 & QJF77808.1 \\
Rhinolophus ferrumequinum & Greater horseshoe bat & 0.00 & BAH02663.1 \\
Rhinolophus sinicus & Chinese rufous horseshoe bat & 0.00 & AGZ48803.1 \\
Rhinolophus ferrumequinum & Greater horseshoe bat & 0.00 & ADN93470.1 \\
\hline
\end{tabular}

Note: $>0.5$ prediction score in our analysis indicate bindiSilvery gibbon2 and SARS-CoV-2 spike.

Abbreviations: ACE2=angiotensin I converting enzyme 2; SARS-CoV-2=severe acute respiratory syndrome coronavirus 2 .

* No common name. 
SUPPLEMENTARY TABLE S4. Results of our predictions and the results of the experimental validation from Yan et al. (8).

\begin{tabular}{|c|c|c|c|}
\hline Sequnece_name & Experiment results & Our prediction sore & Accession number \\
\hline Rousettus_aegyptiacus & Binding & 1.00 & XM_016118926.1 \\
\hline Pteropus_alecto & Binding & 1.00 & XM_006911647.1 \\
\hline Pteropus_giganteus & Binding & 1.00 & GCA_902729225.1 \\
\hline Eidolon_helvum & Binding & 1.00 & GCA_000465285.1 \\
\hline Eonycteris_spelaea & Binding & 1.00 & GCA_003508835.1 \\
\hline Macroglossus_sobrinus & Binding & 1.00 & GCA_004027375.1 \\
\hline Cynopterus_sphinx & Not bind & 0.93 & MT515623 \\
\hline Cynopterus_brachyotis & Not bind & 0.93 & GCA_009793145.1 \\
\hline Rhinolophus_pearsonii & Not bind & 0.09 & MT515622 \\
\hline Hipposideros_armiger & Binding & 0.70 & XM_019667391.1 \\
\hline Hipposideros_galeritus & Not bind & 0.72 & GCA_004027415.1 \\
\hline Hipposideros_pratti & Not bind & 0.70 & MT515621 \\
\hline Megaderma_lyra & Binding & 0.73 & MT515624 \\
\hline Noctilio_leporinus & Binding & 0.77 & GCA_004026585.1 \\
\hline Taphozous_melanopogon & Binding & 0.87 & MT952961 \\
\hline Anoura_caudifer & Binding & 0.72 & GCA_004027475.1 \\
\hline Trachops_cirrhosus & Binding & 0.26 & MT952962 \\
\hline Vampyram_spectrum & Not bind & 0.31 & MT952963 \\
\hline Tonatia_saurophila & Not bind & 0.14 & GCA_004024845.1 \\
\hline Phyllostomus_discolor & Not bind & 0.16 & XM_028522516.1 \\
\hline Carollia_perspicillata & Binding & 0.44 & GCA_004027735.1 \\
\hline Micronycteris_hirsuta & Binding & 0.11 & GCA_004026765.1 \\
\hline Sturnira_hondurensis & Binding & 0.44 & GWHAAZA00000000 \\
\hline Artibeus jamaicensis & Binding & 0.93 & GCA_004027435.1 \\
\hline Desmodus_rotundus & Binding & 0.16 & XM_024569930.1 \\
\hline Pteronotus_parnellii & Not bind & 0.36 & GCA_000465405.1 \\
\hline Mormoops_blainvillei & Binding & 0.38 & GCA_004026545.1 \\
\hline Pteronotus_davyi & Not bind & 0.33 & MT952964 \\
\hline Tadarida_brasiliensis & Not bind & 0.37 & GCA_004025005.1 \\
\hline Molossus_molossus & Not bind & 0.49 & https://vgp.github.io/genomeark/Molossus_molossus \\
\hline Miniopterus_schreibersii & Binding & 0.76 & GCA_004026525.1 \\
\hline Miniopterus_natalensis & Not bind & 0.22 & GCA_001595765.1 \\
\hline Eptesicus_fuscus & Not bind & 0.73 & XM_008154928.2 \\
\hline Aeorestes_cinereus & Not bind & 0.33 & GCA_011751065.1 \\
\hline Pipistrellus_pipistrellus & Binding & 0.36 & GCA_004026625.1 \\
\hline Lasiurus_borealis & Not bind & 0.29 & GCA_004026805.1 \\
\hline Pipistrellus_kuhlii & Not bind & 0.32 & https://vgp.github.io/genomeark/Pipistrellus_kuhlii \\
\hline Antrozous_pallidus & Binding & 0.86 & GCA_007922775.1 \\
\hline Nycticeius_humeralis & Not bind & 0.47 & GCA_007922795.1 \\
\hline Murina_feae & Not bind & 0.48 & GCA_004026665.1 \\
\hline Myotis_myotis & Binding & 0.72 & https://vgp.github.io/genomeark/Myotis_myotis \\
\hline Myotis_davidii & Binding & 0.79 & XM_006775210.2 \\
\hline Myotis_brandtii & Binding & 0.87 & XM_014544294.1 \\
\hline Myotis_lucifugus & Binding & 0.87 & XM_023753669.1 \\
\hline
\end{tabular}

Note: $>0.5$ prediction score in our analysis indicate binding between ACE2 and SARS-CoV-2 spike.

Abbreviations: ACE2=angiotensin I converting enzyme 2; SARS-CoV-2=severe acute respiratory syndrome coronavirus 2. 


\section{REFERENCES}

1. Wang QH, Zhang YF, Wu LL, Niu S, Song CL, Zhang ZY, et al. Structural and functional basis of SARS-CoV-2 entry by using human ACE2. Cell 2020;181(4):894 - 904.e9. http://dx.doi.org/10.1016/j.cell.2020.03.045.

2. Liu YH, Hu GW, Wang YY, Ren WL, Zhao XM, Ji FS, et al. Functional and genetic analysis of viral receptor ACE2 orthologs reveals a broad potential host range of SARS-CoV-2. Proc Natl Acad Sci USA 2021;118(12):e2025373118. http://dx.doi.org/10.1073/pnas.2025373118.

3. Higgins DG, Sharp PM. CLUSTAL: a package for performing multiple sequence alignment on a microcomputer. Gene 1988;73(1):237 - 44. http://dx doi.org/10.1016/0378-1119(88)90330-7.

4. Chan KK, Dorosky D, Sharma P, Abbasi SA, Dye JM, Kranz DM, et al. Engineering human ACE2 to optimize binding to the spike protein of SARS coronavirus 2. Science 2020;369(6508):1261 - 5. http://dx.doi.org/10.1126/science.abc0870.

5. Niu S, Wang J, Bai B, Wu LL, Zheng AQ, Chen Q, et al. Molecular basis of cross-species ACE2 interactions with SARS-CoV-2-like viruses of pangolin origin. EMBO J 2021;40(16):e107786. http://dx.doi.org/10.15252/embj.2021107786.

6. Letunic I, Bork P. Interactive tree of life (iTOL) v5: an online tool for phylogenetic tree display and annotation. Nucleic Acids Res 2021;49(W1):W293 6. http://dx.doi.org/10.1093/nar/gkab301.

7. Damas J, Hughes GM, Keough KC, Painter CA, Persky NS, Corbo M, et al. Broad host range of SARS-CoV-2 predicted by comparative and structural analysis of ACE2 in vertebrates. Proc Natl Acad Sci USA 2020;117(36):22311 - 22. http://dx.doi.org/10.1073/pnas.2010146117.

8. Yan H, Jiao HW, Liu QY, Zhang Z, Xiong Q, Wang BJ, et al. ACE2 receptor usage reveals variation in susceptibility to SARS-CoV and SARS-CoV-2 infection among bat species. Nat Ecol Evol 2021;5(5):600 - 8. http://dx.doi.org/10.1038/s41559-021-01407-1. 